\title{
Living in Transition to Teacher Education in Canada: Personal Reflections and Portraits of Two Vietnamese Female Doctoral Students
}

\author{
Thuy-Hang Thi Tran \\ Ho Chi Minh City University of Technology and Education, Vietnam \\ Tram-Anh Bui \\ Brock University, Canada \& Ho Chi Minh City University of Foreign Languages and Information Technology, \\ Vietnam
}

\begin{abstract}
Living in transition while studying teacher education leads to multiple challenges for doctoral students as they situate themselves in the intersections with new sociocultural environments. The navigation process affects their personal and professional self-formation in constructing and reconstructing their multiple identities-making. In this paper, we, two Vietnamese female teachers, examine our life experience transitioning from Vietnamese to Canadian culture while pursuing our doctoral studies. The collaborative autobiography allows us to reflect, retell and relive our stories since we arrived in Canada. Through deconstructing our stories, we were amazed at the resonances of our tensions in new life-making experiences and perspective transformation in learning and conducting research. We hope our experiences are promising to shorten the gap in understanding experiences of those doctoral students composing life in similar education landscapes, which helps ease their difficulties and cultivate their academic and professional achievements. We also contribute more personal, social, cultural, and familial narratives to the dominant institutional narratives of Canadian teacher education.
\end{abstract}

Keywords: life in transition; international doctoral students; collaborative autobiography; flourishing

\section{Introduction}

As two international doctoral students composing lives in transition, we see how our experiences have shifted over time, place and relationship in our teacher education journey. When living, telling, reliving and retelling our stories, our embodied experiences shaped the opportunities for more possibilities in the future of our studying, working, and living journey. Employing collaborative autobiography (Lapadat, 2009), we explored how we could relate to each other's individual experiences and respond to what we shared with openness and respect in capturing our emotions through various ups and downs of life in transition in teacher education. We believe that sharing our understanding of our storied experiences in transition to the teacher education program in Canada may pave the way for deeper understanding toward 
experiences of other international students.

\section{Shifting from a "Very Young" Teacher in Vietnam to an Under-Represented Doctoral Student in Canada: Tram-Anh's Experiences}

First days I came to teach at a university

I was stopped by a campus guard at the entrance

He asked me, "Where are you going? Where is your student card?"

I said, "Sorry I'm going to my class to... teach."

On the hallway, some students bumped to me and said,

"Sorry my friend, I am late, and I need to run."

Later, the same group of students were surprised

When they saw me entering the class and approaching the teachers' desk.

They asked, "are you a teacher?" "Yes, I am”, I answered.

After the class, I entered the teacher's room

I overheard a colleague's voice, "do you know who is teaching that class?"

"She looks like a student, not a real teacher."

"I don't think she could be a teacher; she is too young."

The conversations above happened when I started my career at a Vietnamese university, where I had earned my bachelor's degree in English teaching. The experience of first being mistaken as a student and then being identified as a young teacher made me wonder who I was in their eyes: a young and enthusiastic teacher or an immature and less experienced one.

I experienced imposter syndrome when I entered my professional teaching career. I learned not to compare myself with experienced teachers but to search for my path building up my teacher identity. I did not react towards the dominant professional teaching stories in which people tend to connect teaching professions with senior individuals. Rather, I silently focused on developing my career through learning and improving my teaching practice and relationships with students. I saw myself in the role of a companion sharing learning experiences and knowledge with students, and I kept trying to progress towards the attainment of my academic and professional goals. In return, they saw me as their sister or even named me as a lollipop teacher, a sweet, friendly, and approachable teacher with whom they could share their academic matters and personal concerns.

I found happiness in teaching at the university; however, I saw myself as a teaching machine trying to finish one class and rushing into another one. Sometimes, my teaching 
practice was greatly influenced by the international language standardized tests that require students to learn for the specific test-related content to graduate. The test-driven lesson plans made me wonder about the authentic meaning of teaching and learning. In searching for my path of meaning-making, I learned that in-depth knowledge of research and teaching practice through professional development is important. The passion and the need for my professional growth brought me back to my dream of studying in an internationally recognized educational system. These events contributed to my decision to embark on further studies at a doctoral level at a Canadian institution. I was admitted as a $\mathrm{PhD}$ student by a Canadian professor, whom I thought would share my interests in English language assessment for Vietnamese teachers.

Before entering my doctoral program, I had married and came to Canada as a newlywed, and my husband and I learned to navigate ourselves and searched for jobs relevant to our professional backgrounds. Our young marriage was also challenged by different obstacles, such as, when my husband found employment in another province, I had to decide whether to support his career and nurture our family life there or stay where my campus was located and maintain my academic commitment. I consulted with my original supervisor, who decided to abandon me when I told him about my dilemma. This was the moment that I most needed his support, and I felt deserted. I wondered if I were qualified enough to further pursue my doctoral work. As a result, I decided to relocate with my husband for a short time and support him in his new endeavours. Later, when I decided to return to campus alone, loneliness soon followed. Tension also intensified when I tried to look for a part-time academic job, but was unsuccessful, due to my lack of cultural experience in Canada. These challenges shifted my positionality from a very young teacher in Vietnam to the inferior situation of being a racialized female doctoral student in the Canadian education landscape.

Fortunately, during this process, the instructor of my first doctoral course agreed to be my supervisor. I also received support from her husband, a professor emeritus, who gave me useful academic advice and showed empathy. They were my magic helpers (Campbell, 2008), supporting me over an important academic threshold. The stories and experiences they shared with me in academia raised my confidence to keep moving forward on my academic adventure. They identified themselves as academic rescuers. I felt privileged to be among the students they rescued academically and emotionally. Their personal and professional life devoted to supporting students, especially those from under-represented groups, definitely (re)shaped my way of thinking about the meaning of being an educator and a researcher.

As I moved along my path of professional growth, I became enlightened as I explored my transition from being a teacher in my home country to being a life-long learner in a 
transnational space. It was in this new space that I shifted my doctoral research interest to explore intercultural competence development of international graduate student leaders who are coping with cultural differences in Canada and who desire to develop their intercultural competence. I accepted the disequilibrium of my teacher education journey as not being a trouble-free path, but a path with heart (Drake, 1991). The disequilibrium and disorienting dilemma I encountered has contributed to my transformation in developing resilience, tenacity, and perseverance (Mezirow, 1991; Thich Nhat Hanh, 2014).

\section{A Mother Living Alongside Young Children Within and Across Doctoral Journey: Thuy- Hang's Experiences}

First days in Canada,

Joey and Sherry were so excited

to see the new school without a fence.

Cheerfully, they shouted in Vietnamese:

"Truờng học không biên giới"

("The school of no border").

Time flies and the Learning Celebration comes.

Mr. S, who was Sherry's Grade One teacher

felt not content with Sherry's reading level.

He suggested it should be level " $E$ " instead of " $C$ ".

Sherry cried;

Ifelt hurt.

Mr. S also said to me,

"You should not use mother tongue often in home places,

but it should be balanced with using English."

I wonder

how he opposed our home language,

and how this helped improve Sherry's reading level.

Why did school disengage my child's mother language

and not support her sustaining of Vietnamese culture 


\section{in her identity making and life-composing?}

In the summer of 2015, I brought my children to Canada to pursue my dream of a $\mathrm{PhD}$ program in teacher education at a Western university. At that time, I carried along my research proposal on Vietnamese teacher professional development that I had nurtured for a long time as a university lecturer in Vietnam. However, it was the experience of a mother living alongside young children that sharply contributed to shifting my doctoral research focus. As seen in the above poem fragment, initially my children were excited to enter their new school which they had named 'the school of no border,' because our earlier experiences in Vietnam conveyed images of schools with fences as borders. However, as life unfolded, more and more borders became visible in their institutional, cultural, personal and linguistic narratives. The Learning Celebration night at Sherry's school was an example of this, as my child and I did not experience this event as a celebration of her learning; rather, it was full of tears, tension, and shamefulness when being criticized by her teacher.

Since that unforgettable moment, I kept wondering if I was a failure as a mother, who had been a teacher before transitioning to Canadian education and not able to support my child in her learning. I felt upset and lonely, but at the same time, I became determined to seek ways to understand and better support my children's experiences. Furthering my thoughts as both a newcomer mother and a doctoral student in elementary education, I wonder about the other Vietnamese newcomer children and mothers' experiences in relation to their new education landscapes in Canada.

Significantly, my doctoral research passion shifted to a new pathway: I longed to conduct a narrative inquiry into the experiences of Vietnamese newcomer children and mothers who are composing lives in transition to Canada. I longed to understand their institutional, social, personal, traditional, cultural, familial, historical, political, and linguistic narratives to help ease their difficulties and facilitate their flourishing.

As I moved deeper into my doctoral program, I saw vividly that my children had not only been the inspiration for my research but also my great companions. During my coursework, I brought Sherry to my classrooms with my professors' permission because she attended halfday Kindergarten, and I could not afford her daycare. Although my learning was filled with challenges, going to campus with Sherry could not trouble me. Rather, having Sherry in a classroom corner while attending lectures and discussions about teaching young children strengthened my reasons to become a teacher educator in elementary education. I came to learn that being a newcomer mother who also worked part-time to support her family and a doctoral 
student was not impossible and that wearing three hats at the same time was not a deficit but truly an asset for my experiences.

Being alongside my children in an academic journey also paved the way for my understanding of reciprocal learning among us. We had days and nights reading books, learning Vietnamese, painting canvases, doing craftwork, and cooking traditional dishes. Beautifully, these activities not only created joyful moments and mental support for our difficulties amidst transition, but they also helped sustain our home language, traditions and culture. My children taught me new ways of learning when we co-composed our home curriculum. I also learned deeply about Canadian culture at elementary schools from my children's stories shared during walks home after school.

My children helped me to further my emerging professional understanding of the relation among schools, families and communities, and to bring my knowledge from the coursework into practice. Meaningfully, all these experiences increased my awakening to the familial curriculum making world (Huber et al., 2011), which later became a significant theoretical concept and practice of my doctoral research. It also showcased the richness of newcomer children and mothers' experiences in their familial, cultural, traditional, and personal contexts which may create bumping against the dominant institutional and social narratives but importantly contributed to the understanding of their life-composing experiences in the transition to Canada.

\section{Finding a Place for Flourishing in Academia: Tram-Anh's Hope and Dream}

During the summer of 2018, I began to participate in a cohort writing group. We, a group of three female PhD students from different cultural backgrounds, ethnicities, and at different stages in life, came together to support each other in writing our doctoral work and learning the conventions of academic writing. Since we were in the same $\mathrm{PhD}$ program, we had opportunities to build trust prior to our writing community establishment. Our group members included an Indigenous person with Objiway bloodlines who was working on integrating Indigenous ways of knowing in teaching and researching. Another woman, who positioned herself in the mainstream culture, explored how her cultural and academic beliefs fit well with her family values. I was the last member of the group, an international student from Vietnam.

We understood that family perceptions, cultural heritage, and native language fluency affect acculturation into academia. We came to academia not only to learn to acculturate but also to bring our values and missions to it, raising our voices for the communities we were from and for whom we were working for. We experienced acculturation into academia differently 
due to our diverse cultural and academic backgrounds. We created opportunities to reflect on our personal and cultural values and helped each other develop our academic writing skills through organizing various group activities and by sharing reflections.

Our group meetings typically began with sharing reflections from the previous meeting. To me, this sharing time was very meaningful, as I usually received understanding, encouragement, and empathy from the other members. We then shared our writings and commented on each other's work. Participating in this writing community allowed me to see myself from different perspectives, contributing to my insight of the self and my awareness of Vietnamese culture. I explored my personal and professional self in relation to others. My selfexploration came from diverse cultural interaction and different contemplative practices considering an ongoing self-reflective process forming my professional identity as an emerging researcher in intercultural and international education.

Through these interactions, I sometimes found myself surprised when some of the 'truths' rooted in my way of knowing were seen and interpreted from different perspectives. I continuously contemplated my intercultural experiences to re-self in a new cultural setting and how this understanding could influence my teaching practice to enhance intercultural competence for international students.

In March 2020, when our university became abandoned as COVID-19 spread, we had to stop our in-person meetings, and, like myself, many international students experienced loneliness and uncertainty. We faced the dilemma of staying in Canada or returning to our home countries, which led to feelings of stress and depression. We had invested our time and financial resources to be immersed in the host culture, but the current situation was difficult. Fortunately, it was during the global pandemic that the members of the writing group found ways to continue to support each other, by embracing technology, which allowed us to offer our presence and deep listening.

Significantly, I considered my writing group as a community of practice and a third space where I sought purposeful social and academic interactions with diverse intercultural, educational, and enjoyable activities, which, in turn, contributed to an understanding of myself and the others. Moreover, as each member endeavored to create a judgement-free and inclusive space, my voice was heard, and I had a sense of belonging.

\section{Living the Relational and Ethical Responsibilities: Thuy-Hang's Experiences from the Research Issues Table to Becoming a Narrative Inquirer}

I still remember the first time I came to campus and joined a weekly meeting at the 
Research Issues Table (RIT) at the Center for Research for Teacher Education and Development at my Canadian university. I was jet-lagged, but the excitement of sitting at the same table and having tea with my supervisor, other professors and graduate students invigorated me. That day the table was filled up with stories people shared about their research and their lives. When the Research Issues bracelet was passed to me, I was encouraged to tell my stories. I cried when I talked about my 40 hours flight and a sleepless night on the floor of Vancouver airport. However, my tears were slowly washed away as others at the table asked me about my experiences. I was moved as people showed me that they were not just listening to my stories but also thinking about them.

Through these and many subsequent moments that I have lived at the RIT, I learned that lives and narrative story-based thinking mattered. I also learned that the shaping of this beautiful table was inspired by the Indigenous knowledge of the talking circle, a physical and spiritual space where attendants are equal and living/studying with/from others in a spirit of respect. Centered at the table, the research bracelet curates a sharing circle and circulates the Indigenous people's spirit of living in relation around members. Every Tuesday I came early and enjoyed watching people gradually entering the room, lunch boxes in hand. At the table we not only contributed to the ongoing conversations, but also participated in monthly seminars on reconsidering teacher education with speakers who were professors and community members such as Elders and other Knowledge Holders.

Importantly, I learned that people joined the RIT excited to hear stories of people from diverse backgrounds, languages, cultures, traditions and histories. The other participants loved to hear and learn from my stories, and I felt a close connection with the others in the conversation circle. As a newcomer student I found the RIT a safe space where I could share my voice, my stories and wonders of my research, and where I could cry and feel loved and cared for, and where I could flourish.

Further, at the RIT, I found a passion for narrative inquiry, which I had never known before transitioning to Canada. Significantly, the RIT was truly my second home, a home of professional and mental support for me as an emerging researcher and teacher educator, a doctoral candidate and a narrative inquirer. It was the knowledge that I learned from people around the RIT, the lessons from my coursework professors and friends, my response group, and my tirelessly supportive supervisor who made me aware that my experiences in academia were relational and ethical.

Six years have passed, and I am now almost finished with my research journey. As I look back on two years of co-composing the narrative inquiry, I learned that living in relationality 
has opened potentials for rooting and sustaining relationships. With three child-mother participant pairs, I have been invited to be alongside them not only as their co-researcher but also as an auntie, a friend, a sister and an advocate. If the relational, ethical responsibilities of a narrative inquirer were not grounded in my journey, I would not be brave enough to stand up and become an advocate for a child and her mother as they moved from a troublesome situation at one school to a new one with better experiences.

It was also during the co-inquiry journey, we checked in on each other's health, safety, and wellness. Many times, we shared smiles, tears and tensions, and supported each other and strengthened our relationships. In living the relational and ethical relationships, I conduct my doctoral research for my people: the current Vietnamese newcomer children and their mothers and families in Canada; the potential-immigrant children, mothers, and families; the Canadian schools, teachers, policymakers, newcomer agents, and cultural brokers who are supporting newcomer children and families.

\section{Retelling Our Stories and Contemplating Our Experiences}

We learned from Lapadat (2009) that "in collaborative autobiography, co-researchers cycle through sequences of oral and written interaction to express, witness, understand, and ultimately act on their own and others' autobiographical narratives" (p. 958). Over four years, we have written our narratives since we first came to Canada as international doctoral students, with much living, telling, reliving and retelling (Clandinin, 2013) toward our experiences.

Our process of sharing and resharing our stories and reflective entries as well as our ongoing reflective conversations, happened through a variety of channels, from video and audio calls to sending messages back and forth, and in-person meetings when we attended national and international conferences together. Data were not our stories, but our understanding of our experiences lived in the stories. Our stories during our collaborative workin-progress reflected how we learned to navigate, situate, and help ourselves flourish in a new academic and social environment. Revisiting our experiences, we paid attention to the resonant threads that "echo and reverberate with each other" (Clandinin \& Connelly, 2004). We came to identify three resonances in our experiences of composing life amidst our doctoral journey as international students and either a wife or a mother.

\section{Entering a Doctoral Student's Life with Borderland - Visible and Invisible}

Before transitioning to Canada for our graduate study, we both carried hopes and dreams to our new place. Longing to develop our home country's teacher education, our original 
research proposals had focused on language teacher professional development in Vietnam. However, soon after we crossed the Canada border, our feet stepped into many other visible and invisible "borderlands," which later contributed to shifting our doctoral research passion. With excitement, we had expected to start a good chapter of life in academia and in family, but things happened differently.

As in Thuy-Hang's stories, she has experienced many of her children's borderlands in a new language and new culture at their school of no border. It was her children's tears and tension triggering her ambition in conducting research to understand their experience of composing life in transition, and also that of other children and mothers of Vietnamese ancestry, who are newcomers in Canada.

For Tram-Anh, rather than having an exciting family life, the new bride had to overcome various borderlands: the failure of getting an academic job due to her lack of Canadian experience and living distant from her spouse. Struggling more, she faced the hardest time in a doctoral student's life, lacking supervision from her original supervisor. Staying strong, TramAnh deeply contemplated the question to understand herself, and she found meaning in shaping her current research puzzle of exploring the intercultural competence of international graduate student leaders.

Obviously, when we entered our overseas doctoral journey, we had not imagined the many ups and downs in those visible and invisible borderlands, which remarkably impacted our research foci. Writing and telling our stories with smiles as well as tears, tensions, loneliness, silence and fears in relation to visible and invisible borderlands opened a window for our sharing with each other, which, in turn, helped us gain a better understanding of our experiences.

\section{Awakening to Multiple Senses of Self in Academia}

Entering our doctoral journeys with obstacles, both of us, Vietnamese female students, told ourselves to never give up, but to keep hope and move forward. We have carried our homeland's cultural life mantras of 'Family First' and 'Keep Balance' for Vietnamese women, so that everything we do makes meaning for ourselves and our loved ones. Living in this new country, our partners and children are the only intimate support through all lows and highs of the journey; therefore, we are happy when they are happy and vice versa. Thuy-Hang had to find a part-time job to learn the Canadian ways of working and to secure her family finances. With Tram-Anh, she had been working and encouraged her husband to work in a place far from her, as she believed this was a good opportunity for him to earn his own Canadian work 
experience. Significantly, we found meaningful identities either as a mother trying to sustain the homeland's language and culture for children, or as a new bride learning to navigate family life in a new country and a member of a new living community.

As international doctoral students, we either lost our original research initiative or a program supervisor at first. But life found a way when our learning approach shifted from a traditional single way to the reciprocal intercultural one (Soong et al., 2015). As emerging researchers, we learned that research could start from our own selves, and that it could happen when the methodologies chose the researchers. For Thuy-Hang, her research was grounded in experiences (Dewey, 1938) and that was the way narrative inquiry methodology (Clandinin \& Connelly, 2004) had chosen her. Thuy-Hang's experiences in sustaining the homeland language, culture, and tradition for the children together with their adaptation to the Canadian landscapes had shaped her understanding of who she was and who she was becoming in the world of academia. It was in her embodied knowing and being in relation that Thuy-Hang pursued the journey of becoming a narrative inquirer. For Tram-Anh, the rigid connection with concentric stories (Drake \& Elliot, 1999) and contemplative qualitative inquiry (Janesick, 2016) shaped her research in constructing international students' intercultural competence. Tram-Anh's life-making in transnational space unfolds her experience as an intercultural learner and a cross-border emerging researcher.

Collectively, living multiple selves in our bodies was not troubling our identity making in both family and academic life; rather, this experience contributed to enrich our knowledge during our doctoral journey. As we saw our relationship as sister scholars in Canadian postsecondary institutions, "we walk for ourselves; we walk for everyone; always hands in hands" (Thich Nhat Hanh, 1993, p. 174). The more we learned from this walking spirit and learned with each other, the more we were drawn to empathy and compassion to our stories and many stories of others who may have experienced similar walks.

\section{Nurturing an Alone-but-Not-Lonely Doctoral Journey in Teacher Education}

Being in our programs with many tensions, we found the essence to look for support resources in our surroundings. As always, our first and foremost supporters were our family members who are always alongside our challenges and rewards during our study. Thuy-Hang had carried her mother's wisdom to Canada, "doing a $\mathrm{PhD}$ is a triple difficulty for a mother with young children in a strange country; thus, it is vital to find happiness for yourself, from people in your surroundings and even from smallest things in nature.” Tram-Anh's parents kept reminding her of her new-established family which always needed her presence, love, and care. 
Many times, we have travelled mentally and spiritually back to our great families in Vietnam to seek for wisdom and insights into ways of navigating and sustaining our family life.

Pursuing our doctoral research, we knew that our pathway had begun during many other events, and we were the independent walkers, but we did not feel lonely. As we walked alongside each other and the other people around us, we were, at the same time, also accompanied by our response communities. Thuy-Hang has deeply loved her Research Issues Table as it nourished a non-judgmental, ethical, relational, and caring environment for graduate students of diverse backgrounds, and emerging scholars to feel safe and encouraged to have their stories heard. Accordingly, the table contributed to provide sustainable growth for people sitting around it and help them excel in their multicultural and multilingual strengths. ThuyHang also saw the table as paving a new "immediate affiliate", which potentially gathered the brave people who dared to become the change makers for a world-wide education of diversity, equity and inclusion.

Thuy-Hang's second response community was her supervisor and other doctoral students under the same supervision. Tram-Anh had long been treasuring the support within her cohort group, who made her flourish in both academic journey and daily life. Blending ourselves in these response communities, we shared research writings, questions, and wonders with other community members to seek their feedback and advice. This experience also happened in reciprocal ways as we were willing to read our peers' works and share our feedback. It was also a time when we shared with our response communities about those bumping institutional, social, and cultural narratives that we experienced on campus and elsewhere across our doctoral life.

Additionally, both of us grew up in Vietnamese culture and tradition, one that sees females as an inferior gender, landed in Canada with Western culture, and attended doctoral programs where academic English was dominant, and we were awakened to find support from people who speak the same language and live in the same culture. We each looked for a soulmate in academia through some international Vietnamese academic networks and international conferences until we found each other and grew our kinship as 'sister scholars'. It was speaking the same home language, living the same culture, and sharing the same favorite Vietnamese cuisine that brought the two of us closer for better understanding of our experiences in transition. Not only have we supported each other in personal and professional life, but we have also co-composed academic journal articles and furthered collaborative projects in teacher education bridging the two nations: Vietnam and Canada. 


\section{Conclusion}

Moving beyond the stories in our autobiography, we have been awakened to the possibilities of unpacking our experiences as Vietnamese female doctoral students in Canada. We see the "attentive necessity of recognizing ways of being, knowing, and remembering in our lived, told, retold, and relived experiences of composing lives in transition" (Tran, 2019, p. 15). Our forward-looking thoughts and imaginings shape three meaningful points.

Firstly, we enhanced our understanding of Thich Nhat Hanh's (2014) idea of 'no mud, no lotus,' which suggests that the Vietnamese lotus grows from the mud and blooms with beauty and fragrance. Similarly, our doctoral journey started with unexpected difficulties, but we were gratefully able to receive support along the way that have enabled us in transcending over thorny rocks, transforming our perspectives, and flourishing in our academic and personal life.

Secondly, we allowed our vulnerable selves to be exposed so that we could open doors to receive sharing, empathy, and compassion from others. Walking across our various senses of selves, we made meaning of our identity-making in combination within our mind and body, contributing to our knowledge of who we were in academia and who we were becoming within, between, and across the two cultural spheres.

Thirdly, we came to learn the value of response communities as featured as "playfulness, mutual responsibilities, understanding the multiplicity of tensions, relational ethics/the ethics of friendship, imagination, safety, and staying with ideas in other places" (Caine et al., 2020, p. 1). We were grateful to be surrounded and supported by our supervisors, the graduate students in our cohort, the researchers whom we met on campus and elsewhere.

Indeed, from our experiences, we imagine a space where international doctoral students from diverse cultural, social, academic, and linguistic backgrounds could grow the seeds of hope in their study and receive ongoing support during their programs. The Research Issues Table in Thuy-Hang's stories and the Cohort Writing Group in Tram Anh's stories are promising examples of this space, which should be multiplied to the wider community to really listen to and better understand the challenges that minority groups may face during their time being stuck in institutional narratives.

Having a safe and informal space at an institution will also help ease tensions of bumping narratives against the dominant culture in teacher education and facilitate anti-racism. Within this space, every student can offer their full presence and deep listening for one another as ways to be in sharing and being shared. They can also practice 'world'-travelling (Lugones, 1987) by travelling to each other's 'world,' they can attend to and understand the others' experiences 
and generate understanding from different perspectives. This spirit of 'world'-travelling is an essential practice between supervisors and graduate students.

Our forward-looking thoughts also promote the images of teacher education flourishing in Canada, where teachers and students make kinship with each other to uplift those in need, especially those from underrepresented groups such as female, black, Indigenous, disabled, 2SLGBTQ+, and individuals coming from low socio-economic status across regions, provinces, and nations of the West and the East.

We are hopeful our experiences open potentialities in understanding the experiences of doctoral students composing life in similar educational landscapes and, thus, pave more ways to ease their difficulties and cultivate their professional and personal achievements. We also long to contribute more personal, social, cultural, and familial narratives to the dominant institutional narratives of Canadian teacher education to shorten the gap between these two landscapes that international and local students are composing their lives with worries and tensions but also hopes for a flourishing future.

\section{References}

Caine, V., Clandinin, J., \& Lessard, S. (2020). Considering response communities: Spaces of appearance in narrative inquiry. Qualitative Inquiry, 27(6), 661-666. https://doi.org/10.1177/1077800420948105.

Campbell, J. (2008). The hero with a thousand faces (3rd ed.) New World Library.

Clandinin, D. J. (2013). Engaging in narrative inquiry. Routledge.

Clandinin, D. J., \& Connelly, F. M. (2004). Narrative inquiry: Experience and story in qualitative research. Jossey-Bass.

Dewey, J. (1938). Experience and education. The Macmillan Co.

Drake, S. (1991). The journey of the learner: Personal and universal story. The Educational Forum, 56(1), 47-59.

Drake, S., \& Elliott, A. (1999). Concentric storying: A vehicle for professional development in teacher education. Paper presented at AERA, Montreal Quebec.

Huber, J., Murphy, M. S., \& Clandinin, D. J. (2011). Places of curriculum making: Narrative inquiries into children's lives in motion. Emerald Group Publishing.

Janesick, V. (2016). Contemplative qualitative inquiry: Practicing the Zen of research. Routledge.

Lapadat, J. C. (2009). Writing our way into shared understanding: Collaborative autobiographical writing in the qualitative methods class. Qualitative Inquiry, 15, 955- 
979.

Lugones, M. (1987). Playfulness, “world”-travelling, and loving perception. Hypatia, 2(2), 319.

Mezirow, J. (1991). Transformative dimensions of adult learning. Jossey-Bass.

Soong, H., Ly, T. T., \& Pham, H. H. (2015). Being and becoming an intercultural doctoral student: reflective autobiographical narratives. Reflective Practice, 16(4), 435-448. https://doi.org/10.1080/14623943.2015.1023276.

Thich Nhat Hanh. (1993). Call me by my true names: The collected poems of Thich Nhat Hanh. Parallax Press.

Thich Nhat Hanh. (2014). No mud, no lotus: The art of transforming suffering. Parallax Press.

Tran, T. T. H. (2019). An autobiographical narrative inquiry into the experiences of a Vietnamese mother: Living alongside children in transition to Canada. In Education, 25(1). 3-18

\section{Authors}

Dr. Thuy-Hang Thi Tran has been a lecturer at Ho Chi Minh City University of Technology and Education, Vietnam since 2010. She completed her PhD in Elementary Education at the University of Alberta, Canada in 2021. She has a wide range of research interests including familial curriculum making, multicultural and multilingual education, elementary teacher education, immigrant children and families, and narrative inquiry. She strongly believes that "relationship is key" in both research and everyday life-making. She can be reached at hangthit@ualberta.ca or hangttt@hcmute.edu.vn.

Tram-Anh Bui is a PhD candidate in Educational Studies at Brock University, Canada and a lecturer at Ho Chi Minh City University of Foreign Languages and Information Technology (HUFLIT), Vietnam. Her major research interests lie in the area of student mobility, international student leadership, intercultural competence, and EFL teacher education. She is also passionate about employing mindfulness and meditation in qualitative inquiry. She can be reached at tb15qg@brocku.ca or buitramanh209@ gmail.com. 